\title{
Antihypertensive peptides derived from food sources
}

\begin{abstract}
High blood pressure or hypertension is a major risk factor for a number of chronic diseases among human beings. A progressive rise in blood pressure can lead to haemorrhagic stroke, myocardial infarction, heart failure, chronic kidney disease, cognitive decline and premature death. The past decade has seen a constant increase in prevalence of hypertension among populations because of changes in lifestyles and dietary patterns. Though pharmaceutics are available, the response to drugs shows variability and outright toxicity in some patients. With prolonged use, side effects of drug tend to manifest in the form of metabolic disorders like diabetes amongst patients. Since food sources have yielded bioactive peptides with antihypertensive properties, they have attracted attention of scientific community. Various methodologies like enzymatic hydrolysis, food fermentation and recombinant DNA technology has been explored for their production from various food sources such as dairy products, cereals, legumes, etc. The review contains an overview of possibilities of commercial exploitation of variety of food sources for production of antihypertensive peptides in functional food or therapeutic forms.
\end{abstract}

Keywords: hypertension, antihypertensive peptides, fermentation, enzymatic hydrolysis, milk products, soy protein
Volume 2 Issue I - 2016

\section{Praveen P Balgir, Tejinder Kaur, Maleeka Sharma \\ Department of Biotechnology, Punjabi University, India}

Correspondence: Praveen P Balgir, Department of Biotechnology, Punjabi University, Punjab, I 47 002, India, Email balgirbt@live.com

Received: October 25, 2015 | Published: January 19, 2016
Abbreviations: ACE, angiotensin-converting enzyme; RAS, renin-angiotensin system; ENOS, endothelial nitric oxide synthase; NO, nitric oxide; LAB, lactic acid bacteria; SHRs, spontaneously hypertensive rats; ECE, endothelin-1 and endothelin converting enzyme; ET, endothelin; MRW, met-Arg-Trp; FPI, flaxseed protein isolate; RPI, rapeseed protein isolate; BSFP, black-bone silky fowl muscle peptides; DBP, diastolic blood pressure; IER, inhibitory efficiency ratio; AHPM, antihypertensive peptide multimer

\section{Introduction}

High blood pressure or hypertension is a serious medical condition, caused due to a high flow of blood through the blood vessels with a force greater than normal. It strains the heart muscles and damages the blood vessels leading to stroke and finally death, if untreated. Untreated hypertension is usually associated with a progressive rise in blood pressure. ${ }^{2}$ It is the most common cause of morbidity and chronic metabolic disorders in the world. It is estimated to affect billions of individuals worldwide affecting $25 \%$ of most adult populations. ${ }^{3,4}$ Hypertension as been called a silent killer as it has been implicated as the underlying cause for development of haemorrhagic stroke, cognitive decline, myocardial infarction, heart failure, chronic kidney disease and premature death. ${ }^{5}$

Hypertension may be classified as essential or secondary. Essential hypertension is the term for high blood pressure with no known etiological cause. Essential hypertension is caused by many factors:

i. genetic predisposition,

ii. lifestyle and environmental influences, and

iii. disturbances in vascular structure and neuro-humoral control mechanisms. $^{5}$

It accounts for about $95 \%$ of cases. Secondary hypertension is the term for high blood pressure associated with a known aetiology such as kidney disease, tumours or birth control pills. At present, it is widely accepted that approximately $30-50 \%$ of cases of hypertension can arise from genetic susceptibility. Monogenic forms of hypertension provide a unique opportunity to study the effects of single gene and identifying pathways and mechanisms leading to blood pressure elevation. ${ }^{6}$ A number of pathways have been involved in the causation of hypertension amongst humans. Prominent among them are the pathways for fluid and electrolyte balance; the reninangiotensin system (RAS), the kinin-kallikrein system, the neutral endopeptidase system and the endothelin-converting enzyme system. Thus in clinical practice, vasodilators, diuretics, calcium channel blockers, angiotensin II receptor blockers and ACE inhibitors have been normally used as drugs. ${ }^{7}$ Most drugs target one or the other pathways to control hypertension. The response to drugs is varied and thus in non-responders may lead to metabolic disorders like diabetes, vascular blockage etc.

Due to a high prevalence of hypertension among human population, a multipronged approach including changes in life-style, dietary approaches and pharmacological treatments is the need of the hour. Peptides of food origin have been reported to play an important prophylactic role in the prevention and/or treatment of hypertension, and therefore, researchers are extensively exploring food based strategies to produce functional food products with antihypertensive properties.

A number of bioactive peptides from food sources have been identified which are known to possess antihypertensive properties. Although milk proteins are still the main source of antihypertensive peptides, recently a remarkable increase has been noticed in the reports of antihypertensive peptides released from other dietary sources. ${ }^{8}$ Such peptides have the ability to modulate the reninangiotensin system (RAS) because they decrease activities of renin 
or angiotensin-converting enzyme (ACE), the two main enzymes that regulate mammalian blood pressure. These antihypertensive peptides can also stimulate the endothelial nitric oxide synthase (eNOS) pathway to increase nitric oxide (NO) levels within vascular walls and promote vasodilatation. The peptides can block the interactions between angiotensin II (vasoconstrictor) and angiotensin receptors, which can contribute to reduced blood pressure. ${ }^{9}$ Studies have reported that peptides derived from protein based food sources such as milk, cereals, soy, etc. are ACE-inhibitory and may thus be used to treat hypertension. Similar to the antihypertensive drugs, different classes of anti-hypertensive peptides are ACE inhibitiory peptides, Renin Inhibitiory peptides, Calcium channel blocking peptides, Opioid peptide vaso-relaxative peptides, Endothelin-1 and endothelin converting enzyme (ECE) in hibitiory peptides reviewed recently by Majumder et al. ${ }^{10}$

\section{Production of Antihypertensive Peptides from food sources}

Antihypertensive peptides have been mainly produced from dairy products such as milk, cheese, etc. However, production from food sources other than dairy has also been carried out recently. These peptides can be produced by one or a combination of following methods: ${ }^{11}$

\section{i. Enzymatic hydrolysis}

ii. Fermentation of protein based food sources

\section{iii. Genetic recombination in bacteria}

Enzymatic hydrolysis by digestive enzymes: According to literature the most common way of producing antihypertensive peptides from food proteins is enzymatic hydrolysis. Many of the Angiotensin Converting Enzyme (ACE) inhibitory peptides have been produced using gastrointestinal enzymes, usually pepsin and trypsin. ${ }^{12,13}$ Enzymes from plant (e.g. Papain) and animal sources (e.g., pepsin and trypsin), have also been used in producing antihypertensive peptides. ${ }^{14}$

A variety of food sources, antihypertensive peptides have been produced using enzymatic hydrolysis. Different enzymes have been used to digest milk proteins to yield antihypertensive peptides. The first study has been conducted in 2004 which yielded lactokin in AlaLeu-Pro-Met-His-Ile-Arg (ALPMHIR) as ace inhibitory peptides. ${ }^{15}$ The latest study on lactoferr in hydrolyzates (LFHs) generated by trypsin and proteinase $\mathrm{K}$ yield different antihypertensive peptides which acts on rennin-angiotensin system (RAS) and the endothelin (ET) system. ${ }^{16}$

Black-bone silky fowl (Gallus gallus domesticus Brisson) muscle has been treated by multistage separation. The black-bone silky fowl muscle peptides (BSFP) was hydrolyzed with Alcalase and papain has been tested for ACE in hibitiory activities. From a total of 29 peptides two novel potent ACE inhibitory peptides Leu-Glu-Arg and Gly-Ala-Gly- have been found. ${ }^{17}$ Hen eggs provide biological functions beyond basic nutrition. In a study, the antihypertensive effect of peptide RVPSL from egg protein decreased the blood pressure of SHRs in 4 weeks. The peptide influenced the expression of major RAS components by down-regulating the renin, ACE, Ang II, and AT1 receptor while upregulating the AT2 receptor in SHRs. ${ }^{18}$ In an another study a tri-peptide IRW (Ile-Arg-Trp) from egg white protein ovotransferrin; demonstrated anti-hypertensive effects of IRW in vivo which is mediated through ACE inhibition and endothelial nitric oxide synthase. ${ }^{19} \mathrm{ACE}$ inhibitory peptides have also been isolated from fish sources. Suetsuna et al., ${ }^{20}$ identified first ACE inhibitory peptide in sardine over thirty years ago. Since then many other peptides have been isolated from various fish species, including shellfish, tuna, bonito, salmon, etc. ${ }^{21}$

Amongst plant sources, Met-Arg-Trp (MRW) isolated from the pepsin-pancreatin digest of spinach lowers blood pressure via prostaglandin $\mathrm{D}(2)$-dependent vasorelaxation in SHRs. ${ }^{22}$ Pea protein isolate, hydrolyzed with alcalase, have proven inhibitory against ACE, renin, and calmodulin-dependent phosphodiesterase 1 (CaMPDE). ${ }^{23}$ Four peptides of sequence: ITP IIP GQY STYQT have been isolated by protease enzyme digestion of sweet potato protein. ITP peptide was found to be the most potent ACE inhibitor as concluded by in vivo study on rats. ${ }^{24}$

Edible mushrooms have also yielded ACE inhibitory oligo peptides. One such peptide with the sequence LSMGSASLSP was isolated in water extracts of mushroom Hypsizygus marmoreus (brown cultivar). The extract from its fruiting body was purified and proven to have antihypertensive action on SHRs. ${ }^{25}$ In an another study, two new ACE in hibitiory peptides from the fruiting body of Pleurotus cornucopiae were purified. Their sequences were determined to be RLPSEFDLSAFLRA and RLSGQTIEVTSEYLFRH with the molecular mass of 1622.85 and $2037.26 \mathrm{Da}$, respectively. ${ }^{26}$ In vivo study on SHRs validated the antihypertensive activity of both the peptides.

Macro-algae have been part of the staple diet in east Asia for centuries and has wide applications in food and pharmaceutical industries. Papain hydrolysates of the crude Palmaria palmata protein release renin inhibitory peptide of the sequence: IRLIIVLMPILMA. The bioactivity of this peptide was confirmed by renin inhibitory assay. ${ }^{27}$

Amongst cereals Wheat gliadin hydrolysates can act as ACE inhibitors. The peptide Ile-Ala-Pro prepared with acid protease decreased the blood pressure in SHRs significantly with intraperitoneal administration. ${ }^{28}$ Arginine-rich peptides from Flaxseed protein isolate (FPI) obtained by enzymatic hydrolysis with trypsin and pronase were observed to produce in vivo vasodilatory effects. The in vivo study on SHRs suggested that the rate of peptide absorption is rapid as compared to amino acids and thus it provides a fast relief from hypertension. ${ }^{29}$ Rapeseed protein isolate (RPI) digested with proteinase, thermolysin, flavourzyme and pepsin produced rapeseed protein hydrolyzates which can be separated into different anti hypertensive peptides. ${ }^{30}$ At large scale the serine type protease Alcalase is most widely used endo-protease in digests of various plant proteins such as rapeseed, canola, sunflower seed protein, soy protein legumes, rice as well as mung and chick beans showing high potency for ACE inhibition. ${ }^{31}$

Antihypertensive peptides produced by fermentation: Many industrially utilized dairy starter cultures are highly proteolytic in nature and can be used for production of antihypertensive peptides by fermentation of dairy products. The proteolytic system of lactic acid bacteria (LAB) such as Lactococcus lactis, Lactobacillus helveticus and $L$. delbrueckii ssp. Bulgaricus consists of a cell wallbound proteinase and a number of intracellular peptidases, including endo peptidases, amino peptidases, tri peptidases and dipeptidases. ${ }^{32}$ 
Based on these peptidases, a number of commercial products have been synthesized for clinical trials for efficacy testing using different hypertensive subjects.

Many dietary proteins, especially milk proteins, contain physiologically active peptides encoded in the protein sequence. These peptides may be released during gastrointestinal digestion or food processing and once liberated, cause different physiological functions. Milk-derived bioactive peptides are shown to have antihypertensive, antimicrobial, immune modulatory, anti oxidative and mineral-binding properties. ${ }^{33}$ Thus fermentation can yield peptides that are ACE-inhibitory and thus blood pressure-lowering, to be derived from milk proteins. Some of these peptides have also been found to have opioid receptor binding properties. ${ }^{34,35}$ A fermented milk product with the biologically active peptides valyl-prolyl-proline (Val-Pro-Pro) and isoleucyl-prolyl-proline (Ile-Pro-Pro) was shown to lower blood pressure in spontaneously hypertensive rats. ${ }^{36}$ It was suggested that small peptides are absorbed from the gastrointestinal tract without being degraded further by digestive enzymes. ${ }^{37}$ Two other peptides (Tyr-Pro and Lys-Val-Leu-Pro-Val-Pro-Gln) that were purified and characterized from fermented milk were also shown to have ACE-inhibitory activity in SHRs. ${ }^{38,39}$ Nurminen et al. ${ }^{40}$ found that alpha-lactorphin (Tyr-Gly-Leu-Phe) also reduced blood pressure in normotensive and SHRs.

Seppo et al. ${ }^{41}$ reported that fermented milk product named Evolus or Kaiku Vitabrand, lowered the blood pressure in hypertensive human volunteers in 8 weeks by $-14.9 \mathrm{~mm}$. Another controlled trial in hypertensive men lowered the systolic blood pressure in two weeks by- $4.3 \mathrm{~mm} \mathrm{Hg}$ and $-5.2 \mathrm{~mm} \mathrm{Hg}$ in 4 weeks. ${ }^{42}$ A study on casein hydrolysate (Ameal Peptide) lowered the blood pressure by $-6.3 \mathrm{~mm}$ $\mathrm{Hg}$ in 6 weeks. ${ }^{43}$

The whey from milk fermented by LAB, Streptococcus thermophilus and Lactobacillus bulgaricus along with protease treatment was fractionated into four fractions by size exclusion chromatography on a Sephadex G-15 column. The fourth fraction showed the highest inhibitory efficiency ratio (IER) and contains the inhibitory peptide Tyr-Pro-Tyr-Tyr, of which the IC50 was 90.91M. The systolic blood pressure (SBP) and diastolic blood pressure (DBP) was reduced by 15.9 and $15.6 \mathrm{mmHg}$, respectively, in spontaneously hypertensive rat (SHR), after 8weeks of oral administration of diluted whey (peptide concentration $4.9 \mathrm{mg} / \mathrm{ml}$ ). Tri peptides IPP and VPP released from casein inhibit ACE and reduce arterial stiffness in humans at micro molar concentrations produced during the fermentation of milk with lactobacilli. ${ }^{33}$

Several novel antihypertensive peptides have been reported in milk fermented with Enterococcus faecalis CECT 5727. Two of the identified peptides LHLPLP and LVYPFPGPIPNSLPQNIPP, showed angiotensin converting enzyme-inhibitory (ACEI) activity with IC50 values as low as $5 \mathrm{mM}$ and showed antihypertensive activity in hypertensive rats. In particular, b-casein f (133-138), yielded a significant antihypertensive effect in these animals. ${ }^{44}$

A total of 75 peptides included in the fraction with molecular mass below 3000 from an 8-month-old Manchego cheese could be identified using HPLC coupled on line to an ion trap mass spectrometer Some previously described peptides with antihypertensive and/ or angiotensin-converting enzyme (ACE)-inhibitory activity were detected. The formation of five active sequences was followed during cheese ripening in four different batches of Manchego cheese.
Two experimental batches of Manchego cheese elaborated with selected bacterial strains with the aim of improve the organoleptic characteristics demonstrated also a good performance in the formation of peptides with ACE-inhibitory activity during cheese ripening. ${ }^{45}$

Over the past decade, there has been a growing interest in the use of food sources other than dairy, for production of bioactive peptides with antihypertensive activity. Cereal based fermented products contain peptides which have a BP lowering effect. ${ }^{46}$ Studies have shown that common foods from animal and plant origin are important sources of bioactive peptides. Plant sources usually include cereals (wheat, barley, corn, rice) pseudocereals (buckwheat and amaranth), legumes (soybean, bean, pea), brassica species and others (sunflower). The presence of bioactive peptides in cereals and legumes can contribute to increase their food protein quality value and add "functionality" to fermented functional foods consumed on a daily basis. ${ }^{47}$

Soy protein foods are fast category products in the food industry with demand for soy ingredients with improved processing characteristics. Fermented soy products, traditionally consumed in Eastern countries, have been also found to be an important source of ACE inhibitory and antihypertensive peptides. ${ }^{4-50}$ A potent antihypertensive peptide has been identified and characterized in a Korean soy product denominated "chunggugjang" and obtained by soy fermentation with Bacillus subtilis CH-1023. ${ }^{51}$ Other ACEinhibitory and antihypertensive peptides have been identified in soy paste ${ }^{52}$ soy sauce, ${ }^{53,54}$ natto and tempeh,${ }^{55}$ and other fermented soy products. ${ }^{56-58}$

Miso paste is a Japanese traditional fermented food, prepared from soy beans mixed with rice fermented with Aspergillus oryzae (rice koji). Since $A$. oryzae protease based casein hydrolysate results in production of two antihypertensive peptides, Val-Pro-Pro and Ile-ProPro, Casein was added to miso paste during miso paste fermentation in order to release angiotensin-I converting enzyme (ACE) inhibitory peptides. Casien miso paste had a higher ACE inhibitory activity as compared to casein-free miso paste after 7 days of fermentation. Further, a significant antihypertensive activity of casein miso paste was observed in spontaneously hypertensive rats compared to water and the general miso paste at a dosage of $1.8 \mathrm{~g}$ of the casein miso paste $/ \mathrm{kg}$ of BW. ${ }^{59}$

The two ACE inhibitory peptide fractions F2 and F3 were isolated after fermentation of soy protein with Lactobacillus casei spp. pseudoplantarum. The peptide analogues of LIVTQ were synthesized based on N-terminal sequence of peptide (F2) Leu-Ile-Val-Thr-Gln (LIVTQ) and effect of individual residues on ACE enzyme were studied. The study determined the importance of glutamine (Q) and threonine $(\mathrm{T})$ residues in ACE inhibition. ${ }^{60}$

Genetic recombination in bacteria: Apart from the above methods for the production of peptides recombinant DNA techniques have also been explored. As compared to the enzymatic method, the advantages of microbiological genetic engineering techniques to prepare AHP include higher peptide yield and lower cost. ${ }^{61}$ The first study involved expression of recombinant human alpha 1-casein in Escherichia coli and its purification. ${ }^{62}$

Another antihypertensive peptide multimer (AHPM) was designed and cloned in an expression vector in E. coli. The release of high active fragments was confirmed by the simulated gastrointestinal digestion from the AHPM. ${ }^{63}$ Antihypertensive peptides with sequences HHL, HVLPVP, FFVAPFPEVFGK, and GHIATFQER have been expressed 
successfully in E .coli. ${ }^{64}$ Peptides expressed in Escherichia coli by a high throughput recombinant expression system have been designed and used widely, though other bacterial system could be used for the production of peptides at similar yields. ${ }^{65}$

\section{Discussion}

In dairy products, the production of ACE inhibitory and antihypertensive peptides in situ aroused a lot of interest from scientists since these impart therapeutic properties to fermented dairy products. During milk fermentation an excessive amount of peptides are liberated from milk proteins as a result of the action of plasmin (indigenous milk enzyme) and proteolytic activity of starter and nonstarter LAB. ${ }^{66}$ Milk fermented with highly proteolytic species of LAB is widely used to increase the amount of bioactive peptides in fermented dairy products. Thus, selecting the right strains or mixture of strains with high proteolytic activity and lytic tendency is big challenge in this approach. Bacterial species ought not to be excessively proteolytic it will spoil the product by other peptides such as bitter peptides but yet should provide a high proteolysis of bioactive peptides such as ACE-inhibitory peptides. Since the concentration of ACE-inhibitory peptides appears to rely on a balance between their formation and degradation into inactive peptides and amino acids subject to storage periods and conditions. Manipulation of bacterial fermentation of milk play crucial role in increasing antihypertensive activity. The enhance anti-ACE-1 activities associated with herbal extracts or type of milk used in fermented milk has been studied. This may imply unique properties of herbal extracts and milk interactions towards preferential formation of bioactive peptides, some of which may be have ACE-inhibitory activity.

Apart from dairy based sources, other dietary sources such as cereals, legumes, fish, egg, plants, etc. have also been reported to produce peptides with blood pressure lowering effects. Peptides from meat, fish and egg have showed significant effect on increased antiACE-1 activities. ${ }^{17,21,67,68}$ Peptides from plants such as pea, spinach; macroalgae and mushrooms have showed significant antihypertensive activities. ${ }^{22,23,25}$ Cereals such as wheat, buckwheat, soybean have also been used for production of antihypertensive peptides. ${ }^{57,58,60}$ Further studies are needed to isolate and identify the bioactive peptides with ACE- inhibitory activities from other dietary food sources.

\section{Conclusion}

It is now well established that peptides derived from diet offer a promising approach in prophylaxis, regulation and even in treatment of hypertension. As peptides are more reactive than proteins, fermentation and enzymatic hydrolysis from food sources seems to be a potential natural source with a need to optimise production technology for antihypertensive peptides. This potential has already been explored in fermented milk and cheese but to generate peptides on industrial scale controlled fermentation techniques, batch fermentors or bioreactors need to be explored and developed. So food need not be the only source of nutrition or energy but can also provide novel therapeutics with no side effects or off target effects. Further apart from conventional food sources, peptidomic, bioinformatics and chemo metric tools and databases need to be exploited in research for food-derived antihypertensive peptides.

\section{Acknowledgements}

The work has been supported by Department of Science and
Technology, Government of India vide Major Research Project no. SR/SO/HS-38/2009.

\section{Conflict of interest}

The author declares no conflict of interest.

\section{References}

1. Chockalingam A, Campbell NR, Fodor JG. Worldwide epidemic of hypertension. Can J Cardiol. 2006;22(7):553-555.

2. Johnson JA, Liggett SB. Cardiovascular Pharmacogenomics of Adrenergic Receptor Signaling: Clinical Implications and Future Directions. Clin Pharmacol Ther. 2011;89(3):366-378.

3. World health organization. Global Health Observatory Data Repository. Geneva: World health organization; 2008.

4. World health organization. Global status report on noncommunicable diseases 2010. Geneva: World health organization; 2011.

5. Williams B. The year in hypertension. $J$ Am Coll Cardiol. 2008;51(18):1803-1817.

6. Murugan M, Ramalingam K, Nazzuredin M, et al. SNP'S and its correlation with hypertension: A comprehensive review. Dent Med Res. 2013;1(1):3-6

7. Mancia G, Fagard R, Narkiewicz K, et al. 2013 Practice guidelines for the management of arterial hypertension of the European society of hypertension (ESH) and the European society of cardiology (ESC): ESH/ ESC Task Force for the management of arterial hypertension. Journal of Hypertension. 2013;31(10):1925-1938.

8. Martinez-Maqueda D, Miralles B, Recio I, et al. Antihypertensive peptides from food proteins: a review. Food Funct. 2012;3(4):350-361.

9. Aluko RE. Antihypertensive peptides from food proteins. Annu Rev Food Sci Technol. 2015;6:235-262.

10. Majumder $\mathrm{K}, \mathrm{Wu} \mathrm{J}$. Molecular targets of antihypertensive peptides: Understanding the mechanisms of action based on the pathophysiology of hypertension. Int J Mol Sci. 2014;16(1):256-283.

11. Korhonen H, Pihlanto A. Food-derived bioactive peptides--opportunities for designing future foods. Curr Pharm Des. 2003;9(16):1297-1308.

12. FitzGerald RJ, Murray BA, Walsh DJ. Hypotensive peptides from milk proteins. $J$ Nutr. 2004;134(4):980-988.

13. Gobbetti M, Stepaniak L, De Angelis M, et al. Latent bioactive peptides in milk proteins: proteolytic activation and significance in dairy processing. Crit Rev Food Sci Nutr. 2002;42(3):223-239.

14. Pihlanto-Leppala A. Bioactive peptides derived from bovine whey proteins: opioid and ace-inhibitory peptides. Trends in Food Science \& Technology. 2000;11(9-10):347-356.

15. Maes W, Van Camp J, Vermeirssen V, et al. Influence of the lactokinin AlaLeu-Pro-Met-His-Ile-Arg (ALPMHIR) on the release of endothelin-1 by endothelial cells. Regul Pept. 2004;118(1-2):105-109.

16. Fernandez-Musoles R, Salom JB, Martínez-Maqueda D, et al. Antihypertensive effects of lactoferrin hydrolyzates: inhibition of angiotensin- and endothelin-converting enzymes. Food Chem. 2013;139(14):994-1000.

17. Gu RZ, Liu WY, Lin F, et al. Antioxidant and angiotensin I-converting enzyme inhibitory properties of oligopeptides derived from black-bone silky fowl (Gallus gallus domesticus Brisson) muscle. Food Research International. 2012;49(1):326-333.

18. Yu Z, Yin Y, Zhao W, et al. Antihypertensive effect of angiotensin- 
converting enzyme inhibitory peptide rvpsl on spontaneously hypertensive rats by regulating gene expression of the renin-angiotensin system. J Agric Food Chem. 2014;62(4):912-917.

19. Majumder K, Chakrabarti S, Morton JS, et al. Egg-derived Tri-Peptide IRW Exerts antihypertensive effects in spontaneously hypertensive rats. Plos One. 2013;8(11):e82829.

20. Suetsuna K, Osajima K. The inhibitory activities against angiotensin I-converting enzyme of basic peptides originating from sardine and hair tail meat. Bull Jpn Soc Sci Fish. 1986;52:1981-1984.

21. Ryan JT, Ross RP, Bolton D, et al. Bioactive peptides from muscle sources: meat and fish. Nutrients. 2011;3(9):765-791.

22. Zhao H, Usui $\mathrm{H}$, Ohinata $\mathrm{K}$, et al. Met-Arg-Trp derived from rubisco lowers blood pressure via prostaglandin $\mathrm{d}(2)$-dependent vasorelaxation in spontaneously hypertensive rats. Peptides. 2008;29(3):345-349.

23. Li H, Prairie N, Udenigwe CC, et al. Blood Pressure Lowering Effect of a Pea Protein Hydrolysate in Hypertensive Rats and Humans. J Agric Food Chem. 2011;59(18):9854-9860.

24. Ishiguro K, Sameshima Y, Kume $\mathrm{T}$, et al. Hypotensive effect of a sweetpotato protein digest in spontaneously hypertensive rats and purification of angiotensin I-converting enzyme inhibitory peptides. Food Chemistry. 2012;131(3):774-779.

25. Kang MG, Kim YH, Bolormaa Z, et al. Characterization of an antihypertensive angiotensin I-converting enzyme inhibitory peptide from the edible mushroom Hypsizygus marmoreus. Biomed Res Int. $2013 ; 283964$

26. Jang JH, Jeong SC, Kim JH, et al. Characterisation of a new antihypertensive angiotensin I-converting enzyme inhibitory peptide from Pleurotus cornucopiae. Food Chemistry. 2011;127(2):412-418.

27. Fitzgerald C, Mora-Soler L, Gallagher E, et al. Isolation and characterization of bioactive pro-peptides with in vitro rennin inhibitory activities from the macroalga Palmaria palmata. J Agric Food Chem 2012;60(30):7421-7427.

28. Motoi H, Kodama T. Isolation and characterization of angiotensin I-converting enzyme inhibitory peptides from wheat gliadin hydrolysate. Nahrung. 2003;47(5):354-358.

29. Udenigwe CC, Adebiyi AP, Doyen A, et al. Low molecular weight flaxseed protein-derived arginine-containing peptides reduced blood pressure of spontaneously hypertensive rats faster than amino acid form of arginine and native flaxseed protein. Food Chemistry. 2012;132(1):468-475.

30. He R, Alashi A, Malomo SA, et al. Antihypertensive and free radica scavenging properties of enzymatic rapeseed protein hydrolysates. Food Chemistry. 2013;141(1):153-159.

31. Pihlanto A, Makinen SA. Antihypertensive properties of plant protein derived peptides, bioactive food peptides in health and disease. HernándezLedesma. 2013. p. 145-182.

32. Christensen JE, Dudley EG, Pederson JA, et al. Peptidases and amino acid catabolism in lactic acid bacteria. Antonie van Leeuwenhoek. 1999;76(14):217-246.

33. Jakala P, Vapaatalo H. Antihypertensive peptides from milk proteins Pharmaceuticals. 2010;3(1):251-272.

34. Meisel H. Overview on milk protein-derived peptides. International Dairy Journal. 1998;8(5-6):363-373.

35. Yamamoto N, Takano T. Antihypertensive peptides derived from milk proteins. Nahrung. 1999;43(3):159-164.
36. Nakamura Y, Yamamoto N, Sakai K, et al. Antihypertensive effects of sour milk and peptides isolated from it that are inhibitors to angiotensin I-converting enzyme. J Dairy Sci. 1995;78(6):1253-1257.

37. Masuda O, Nakamura Y, Takano T. Antihypertensive peptides are present in aorta after oral administration of sour milk containing these peptides to spontaneously hypertensive rats. J Nutr. 1996;126(12):3063-3068.

38. Maeno M, Yamamoto N, Takano T. Identification of an antihypertensive peptide from casein hydrolysate produced by a proteinase from Lactobacillus helveticus CP790. J Dairy Sci. 1996;79(8):1316-1321.

39. Yamamoto N, Maeno M, Takano T. Purification and characterization of an antihypertensive peptide from a yogurt-like product fermented by Lactobacillus helveticus CPN4. J Dairy Sci. 1999;82(7):1388-1393.

40. Nurminen ML, Sipola M, Kaarto H, et al. Alpha-lactorphin lowers blood pressure measured by radiotelemetry in normotensive and spontaneously hypertensive rats. Life Sci. 2000;66(16):1535-1543.

41. Seppo L, Jauhiainen T, Poussa T, et al. A fermented milk high in bioactive peptides has a blood pressure-lowering effect in hypertensive subjects. Am J Clin Nutr. 2003;77:326-330.

42. Mizushima S, Ohshige K, Watanabe J, et al. Randomized controlled trial of sour milk on blood pressure in borderline hypertensive men. Am J Hypertens. 2004;17(8):701-706.

43. Mizuno S, Matsuura K, Gotou T, et al. Antihypertensive effect of casein hydrolysate in a placebo-controlled study in subjects with high-normal blood pressure and mild hypertension. Br J Nutr. 2005;94(1):84-91.

44. Quiros A, Ramos M, Muguerza B, et al. Identification of novel antihypertensive peptides in milk fermented with Enterococcus faecalis. International Dairy Journal. 2007;17(1):33-41

45. Gomez-Ruiz JA, Ramos M, Recio I. Identification and formation of angiotensin-converting enzyme-inhibitory peptides in Manchego cheese by high-performance liquid chromatography-tandem mass spectrometry. J Chromatogr A. 2004;1054(1-2):269-277.

46. Malaguti M, Dinelli G, Leoncini E, et al. Bioactive Peptides in Cereals and Legumes: Agronomical, Biochemical and Clinical Aspects. Int J Mol Sci. 2014;15(11):21120-21135.

47. Ortiz-Martinez M, Winkler R, Garcia-Lara S. Preventive and therapeutic potential of peptides from cereals against cancer. $J$ Proteomics. 2014;5(111):165-183

48. Kodera T, Nio N. Angiotensin converting enzyme inhibitors. 2002;18:43.

49. Cha M, Park JR. Production and characterization of a soy protein-derived angiotensin I-converting enzyme inhibitory hydrolysate. $J$ Med Food. $2005 ; 8(3): 305-310$

50. Wu J, Ding X. Characterization of inhibition and stability of soy-proteinderived angiotensin I-converting enzyme inhibitory peptides. Food Res Int. 2002;35(4):367-375.

51. Korhonen H, Pihlanto A. Food-derived bioactive peptides--opportunities for designing future foods. Curr Pharm Des. 2003;9(16):1297-1308.

52. Shin ZI, Yu R, Park SA, et al. His-His-Leu, an angiotensin I converting enzyme inhibitory peptide derived from Korean soybean paste, exerts antihypertensive activity in vivo. J Agric Food Chem. 2001;49(6):3004 3009 .

53. Okamoto A, Hanagata H, Matsumoto E, et al. Angiotensin I converting enzyme inhibitory activities of various fermented foods. Biosci Biotechnol Biochem. 1995;59(6):1147-1149.

54. Nakahara T, Sano A, Yamaguchi H, et al. Antihypertensive effect of 
peptide-enriched soy sauce-like seasoning and identification of its angiotensin I-converting enzyme inhibitory substances. J Agric Food Chem. 2010;58(2):821-827.

55. Gibbs BF, Zoygman A, Masse R, et al. Production and characterization of bioactive peptides from soy hydrolysate and soy-fermented food. Food Res Int. 2004;37(2):123-131.

56. Rho SJ, Lee JS, Chung Il Y, et al. Purification and identification of an angiotensin I-converting enzyme inhibitory peptide from fermented soybean extract. Process Biochem. 2009;44(4):490-493.

57. Li FJ, Yin LJ, Cheng YQ, et al. Comparison of angiotensin I-converting enzyme inhibitor activities of pre-fermented Douchi (a Chinese traditiona fermented soybean food) started with various cultures. Int J Food Eng. 2009;5(2):10.

58. Ibe S, Yoshida K, Kumada K, et al. Antihypertensive effects of natto, a traditional Japanese fermented food, in spontaneously hypertensive rats. Food Sci Technol Res. 2009;15(2):199-202.

59. Inoue $\mathrm{K}$, Gotou $\mathrm{T}$, Kitajima $\mathrm{H}$, et al. Release of antihypertensive peptides in miso paste during its fermentation, by the addition of casein. $J$ Biosci Bioeng. 2009;108(2):111-115.

60. Vallabha VS, Tiku PK. Antihypertensive peptides derived from soy protein by fermentation. Int J Pept Res Ther. 2014;20(2):161-168.

61. Lv GS, Huo GC, Fu XY. Expression of milk-derived antihypertensive peptide in escherichia coli. J Dairy Sci. 2003;86(6):1927-1931.
62. Kim YE, Yoon S, Yu DY, et al. Novel angiotensin-I-converting enzyme inhibitory peptides derived from recombinant human as1-casein expressed in Escherichia coli. J Dairy Res. 1999;66(3):431-439.

63. Rao S, Su Y, Li J, et al. Design and expression of recombinant antihypertensive peptide multimer gene in Escherichia coli BL21. J Microb Biot. 2009;19(12):1620-1627.

64. Hernandez-Ledesma B, Contreras M, Recio I. Antihypertensive peptides: Production, bioavailability and incorporation into foods. Adv Colloid Interface Sci. 2011;165(1):23-35.

65. Rodriguez V, Asenjo J A Andrews BA. Design and implementation of a high yield production system for recombinant expression of peptides. Microb Cell Fact. 2014;13:65.

66. Minervini F, Algaron F, Rizzello CG, et al. Angiotensin-I-converting enzyme inhibitory and microbial-bioactive peptides. Int J Dairy Technol. 2004;57:173-187.

67. Shori AB, Baba AS, Keow JN. Effect of Allium sativum and fish collagen on the proteolytic and angiotensin-I converting enzyme-inhibitory activities in cheese and yogurt. PakJ Biol Sci. 2012;15(24):1160-1167.

68. Shori AB, Baba AS, Chuah PF. The effects of fish collagen on the proteolysis of milk proteins in allium sativum-yogurt. Journal of the Taiwan Institute of Chemical Engineers. 2013;44(5):701-706. 